\title{
Prevenção quaternária: a propósito de um desenho
}

Marc Jamoulle*

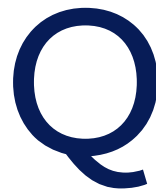

uando tive a ideia da Prevenção Quaternária ${ }^{1}$ o mundo ainda não era global. A Organização Mundial de Saúde (OMS) ainda insistia na lista dos medicamentos essenciais, os países não ocidentalizados não consumiam estatinas e o ataque de pânico ainda se chamava crise de nervos. A depressão ainda não era para tratar sem interrupção e os psicóticos só eram medicados nas crises. A indústria alimentar ainda não era suficientemente eficaz a vender má comida, mas o tabaco já estava em todo o lado.

Numa formação em Saúde Pública, mergulhado em exercícios do $\chi^{2}$, esse teste estatístico que tenta separar o trigo do joio, praticava o cálculo de especificidades, sensibilidades e outros valores preditivos, dos quais se sabe valerem quase tudo para populações, mas nada para um paciente individual. Interessava-me pelos grandes números e pelo seu imenso potencial de predição dos acontecimentos agrupados, mas, depois das aulas, deparava-me com os meus pacientes e com situações tipo «Ele está sozinho com a mulher doente, tem dores de costas e bebe», ${ }^{2}$ que escapam completamente a qualquer autoridade estatística e qualquer previsibilidade.

Fui sempre um desses maus alunos que estão nas aulas lá atrás, longe do olhar inquisidor do professor, mas felizmente a perturbação do défice de atenção sem hiperatividade ainda não existia. Em 1986 mantinha ainda a capacidade de «estar na lua» quando assistia a aulas. Tal explica que durante uma aula de estatística tenha sido levado a fazer um desenhinho no canto inferior de uma folha. Em vez de testar ocorrências, rabisquei uma nova versão de um teste improvável, que testa o médico versus o paciente, o conhecimento de alguns versus a dúvida da maioria e a ciência versus a consciência.

Assim, é possível delimitar quatro possibilidades de acordo ou de desacordo: 1) paciente e médico podem concordar em que não há doença; 2) o médico pode apostar na doença e tentar convencer disso o paciente, que se acha de boa saúde;3) podem ambos estar de acordo sobre a existência de um problema, a necessidade de o tratar e prevenir complicações; 4) pode o paciente sentir-se doente e o médico não encontrar nada, situação deveras frequente e arriscada para o doente. Desta forma interessante, pacientes e médicos encontrar-se-ão forçosamente no ponto ómega, na doença e na morte.

Nesta fase, mergulhei também no Texbook of Family

*Médico de familia. Investigador em Cuidados de Saúde Primários, Charleroi, Belgica
Medicine de McWhinney, regozijando-me com as suas posições para com o homem doente. Alguns anos antes, já me tinha congratulado com a leitura de Illich e, antes ainda, com Balint. No cruzamento da saúde pública com a saúde individual, interrogava-me sobre questões éticas que atravessavam a minha profissão.

Sempre levado a questionar a minha relação com o paciente, passei a interessar-me pelo conceito de motivos de consulta (MC). O professor Henk Lamberts da Universidade de Amesterdão acolheu-me no seio do que ia tornar-se o Wonca International Classification Committee (WICC). Em 1999, o WICC aceitou a definição e o conceito de Prevenção Quaternária foi transcrito no Wonca Dictionnary of General Practice. "Ação tomada para identificar um paciente sob risco de medicalização excessiva, para protegêlo de novas invasões médicas, e para sugerir intervenções eticamente aceitáveis.»

O conceito teria permanecido confidencial e divertido se um dos membros do WICC não tivesse convencido a grande Barbara Starfield ${ }^{4}$ do seu interesse. Ao mesmo tempo, a perceção do mundo mudava em alguns dos meus colegas. Sob a capa da descoberta de novos medicamentos, alimentos e pesticidas, esta indústria tinha recuperado o seu atraso em relação à indústria tabaqueira em termos de nocividade para a espécie humana, em particular, e para a Terra, em geral. Todos se socorriam dos mesmos métodos sofisticados de manipulação da informação e de sedução psicológica - os utilizados pela indústria tabaqueira para incentivar os jovens a pensar que o tabaco não dá dependência. A indústria farmacêutica desdobrou-se em batalhões de delegados de informação médica, em pérolas de engenho para esconder atrás de uma fachada científica a manipulação da informação, a compra de espaços de publicação, a dissimulação de fracassos e o abafar de notícias alarmantes através de um monte de publicações tranquilizadoras pré-pagas. ${ }^{5}$

Mas a capacidade de desvendar informação e de a analisar também se expandiu com determinação. Numerosos médicos e cientistas do mundo inteiro começaram a denunciar manipulações e abusos de todo o género. Nenhum domínio da Medicina atual escapa à crítica. E como nas últimas décadas a Medicina se declarou competente para tudo, da saúde mental à sexualidade, passando pelos comportamentos, as críticas disparam vindas de todo o lado e em particular dos atores dos cuidados de saúde primários, os que estão em contacto diário com a população. 
O domínio das classificações e particularmente o Diagnostic and Statistical Manual of Mental Disorders (DSM) foi um destes campos de batalha, com as revelações das manipulações a que a Associação Americana de Psiquiatria se prestara ${ }^{6}$ Em 1999, fora necessária toda a combatividade de um primeiro grupo de médicos cibernautas e uma primeira petição para impedir que a OMS avalizasse novas normas relativas à tensão arterial, insidiosamente propostas por uma farmacêutica multinacional que tentava alargar o seu mercado. A crise da dita pandemia da gripe abriu os olhos relativamente à influência das empresas sobre os estados e a OMS. Numerosos medicamentos são propostos como panaceias e retirados dos mercados após lutas ferozes nas quais se percebe que os organismos de controlo internacionais são também manipulados por essas mesmas empresas. ${ }^{7}$

Os jornalistas denunciam estas manipulações, ${ }^{8}$ perante as quais a maior parte dos médicos fica impassível ou conivente. Exemplos em que foram ultrapassados os limites do aceitável podem ser detetados em todos os domínios do exercício da Medicina, quer se trate de informação, rastreio, diagnóstico ou tratamento. A Medicina torna-se, pela primeira vez na história contemporânea, suspeita de disseminar a doença. O primum non nocere hipocrático é arrasado por esta civilização de negociantes sem escrúpulos.

Este quadro sombrio assemelha-se à dúvida que invade a prática médica. A inflação de informação, rastreios, meios de diagnóstico e novos tratamentos exige uma sagacidade incrível ao médico que está no terreno, constantemente obrigado a colocar a dúvida no centro do seu processo de decisão.

Neste novo quadro que refina o que em nós restou da abordagem científica, o quadrozinho do $\chi^{2}$ entre o paciente e o médico fornece uma espantosa grelha de observação destes fenómenos. O campo 1 adequa-se perfeitamente à sobreinformação, o campo 2 ao sobrerastreio, o campo 3 ao sobretratamento, ao sobrediagnóstico ou à Medicina defensiva, e o campo 4, que questiona a relação médico-doente, permite-nos também questionar o nosso agir a todos os níveis (Figura 1).

Curiosamente, o meu desenhinho foi recuperado por numerosos médicos e professores a tal ponto que, em 2010, tive a surpresa de me aperceber que jovens estudantes brasileiros de Medicina o conheciam perfeitamente. Difundido por todo o lado pelos colegas do WICC, o conceito instalou-se na Europa e na América Latina e está a caminho da Ásia.

Em 2011, a Equipo Cesca organizou um primeiro seminário pela internet sobre a Prevenção Quaternária. Em 2012, um seminário internacional on line, que terminou com uma jornada de debates em Buenos Aires, reuniu médicos, psicólogos e assistentes sociais argentinos, uruguaios, brasileiros, equatorianos e de múltiplos outros países, para uma discussão inédita sobre a validade da nossa profissão, partindo da grelha de reflexão da Prevenção Quaternária. O conceito de Prevenção Quaternária serve

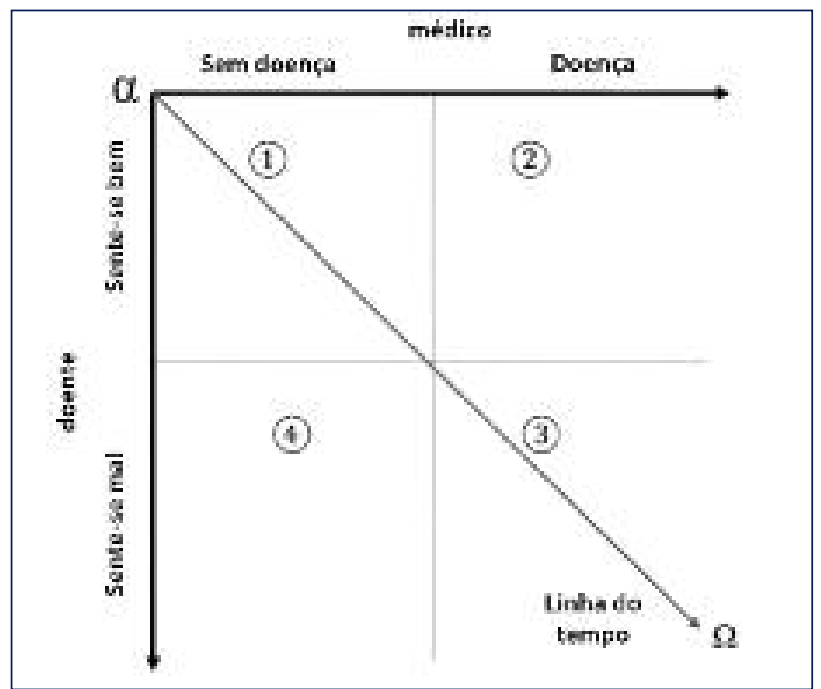

Figura 1. Quatro campos de actividade e prevenção em Medicina.

manifestamente como detonador de uma partilha abrangente de pontos de vista sobre a ética da profissão do prestador de cuidados no mundo global.

Este ano viu morrer dois dos mais eminentes mentores da nossa disciplina, Ian McWhinneye Barbara Starfield, e o conceito de Prevenção Quaternária deve-lhes muito. Sinto-me extremamente honrado e sensibilizado por ser o portador de um pensamento tão fecundo através de uma história inacreditável que começou com um desenhinho num canto inferior de uma página.

\section{REFERÊNCIAS BIBLIOGRÁFICAS}

1. Jamoulle M. Information et informatisation en Médecine Générale. In: Les informa-g-iciens. Namur : Presses Universitaires de Namur ; 1986. p. 193-209.

2. Jamoulle M. Chroniques d'une consultation. Bruxelles: FMM; 1986.

3. Bentzen $\mathrm{N}$, editor. Geneva:Wonca International Dictionary of General/Family Practice:Wonca International Classification Committee; 1999.

4. Starfield B, Hyde J, Gérvas J, Heath I. The concept of prevention: a good idea gone astray? J Epidemiol Community Health 2008 Jul; 62 (7): 580-3.

5. Flanagin A, Carey LA, Fontanarossa PB, Phillips SG, Pace BP, Lundberg GD, et al. Prevalence of articles with honorary authors and ghost authors in peer-reviewed medical journals. JAMA 1988 Jul 15; 280 (3): 222-4.

6. Cosgrove L, Krimsky S, Vijayaraghavan M, Schneider L. Financial ties between DSM-IV panel members and the pharmaceutical industry. Psychother Psychosom 2006; 75 (3): 154-60.

7. Frachon I. Mediator 150 Mg: Sous-titre Censuré. Paris: Brest: Editions-Dialogues.fr; 2010

8. Moynihan R, Doust J, Henry D. Preventing overdiagnosis: how to stop harming the healthy. BMJ May 28; 344: e3502. doi: 10.1136/bmj.e3502

\section{CONFLITO DE INTERESSES}

O autor declara não possuir conflitos de interesses.

\section{ENDEREÇO PARA CORRESPONDÊNCIA}

marc@jamoulle.com

Artigo escrito ao abrigo do novo acordo ortográfico. 